\title{
PELATIHAN LUNGES LEBIH BAIK DARIPADA PELATHAN SQUAT DALAM MENINGKATKAN KEKUATAN OTOT TUNGKAI DAN KESEIMBANGAN ATLET PUTRA PESERAT EKSTRAKURIKULER PENCAK SILAT SMA DWIJENDRA DENPASAR
}

\section{Putu Satriya Yudha Permadi ${ }^{1}$, I Nyoman Adiputra ${ }^{2}$, I Putu Adiartha Griadhi ${ }^{3}$, Putu Astawa $^{4}$, Susy Purnawati ${ }^{5}$, I Dewa Ayu Inten Dwi Primaynti ${ }^{6}$}

${ }^{1}$ Program Magister Fisiologi Keolahragaan Fakultas Kedokteran, Universitas Udayana, Denpasar 2,3,4,5,6 Departemen Ilmu Faal, Fakutas Kedokteran, Universitas Udayana, Denpasar

e-mail: stryydh@gmail.com

\begin{abstract}
ABSTRAK
Kekuatan otot tungkai dan keseimbangan merupakan faktor yang menentukan kualitas tendangan dalam pencak silat, maka diperlukan metode pelatihan tentang kekuatan otot tungkai dan keseimbangan melalui gerakan-gerakan yang lebih efektif. Latihan lunges dan squat merupakan latihan untuk meningkatkan kekuatan otot tungkai dan keseimbangan. Tujuan penelitian ini adalah membuktikan pelatihan lunges lebih baik dari squat dalam meningkatkan kekuatan otot tungkai dan keseimbangan atlet putra peserta ekstrakurikuler pencak silat SMA Dwijendra Denpasar. Jenis penelitian true eksperimental dengan rancangan penelitian randomized pre test and post test with control groups design. Subyek dari penelitian ini atlet putra peserta ekstrakurikuler pencak silat SMA Dwijendra Denpasar yang berjumlah 18 orang yang dibagi dalam dua kelompok yang berbeda. Kelompok 1 latihan lunges sedangkan Kelompok 2 latihan squat, latihan diberikan selama 6 minggu dengan frekuensi 3 kali dalam seminggu. Pengukuran menggunakan alat leg dynamometer untuk mengetahui kekuatan otot tungkai dan standing stork test untuk mengetahui keseimbangan. Hasil rerata pengukuran kekuatan otot tungkai sebelum latihan lunges $177,44 \pm 7,69 \mathrm{~kg}$ sedangkan setelah latihan lunges $205,44 \pm 9,50 \mathrm{~kg}$. Hasil rerata pengukuran kekuatan otot tungkai sebelum latihan squat 172,33 $\pm 7,84 \mathrm{~kg}$ sedangkan setelah latihan squat 187,22 $\pm 7,32 \mathrm{~kg}$. Hasil rerata pengukuran keseimbangan sebelum latihan lunges 18,11 $\pm 1,61$ detik sedangkan setelah latihan lunges 27,22 $\pm 1,98$ detik. Hasil rerata pengukuran keseimbangan sebelum latihan squat 18,44 $\pm 1,87$ detik sedangkan setelah latihan squat 23,11 $\pm 1,36$ detik. Uji beda rerata kekuatan otot tungkai dan keseimbangan pada Kelompok 1 dan Kelompok 2 dengan uji independent pada post test didapat hasil nilai $\mathrm{p}=0,00$ $(\mathrm{p}<0,05)$. Kelompok 1 dan Kelompok 2 sama-sama memberikan peningkatan terhadap kekuatan otot tungkai dan keseimbangan pada atlet putra peserta ekstrakurikuler pencak silat SMA Dwijendra Denpasar, tetapi Kelompok 1 lebih baik dari pada Kelompok 2 dilihat dari rerata post test. Saran dalam penelitian ini diharapkan kepada para pelatih dapat memberikan latihan dengan tepat dan sesuai dengan metode dan prinsip dalam pelatihan agar mampu meningkatkan prestasi atlet.
\end{abstract}

Kata Kunci: Kekuatan Otot Tungkai, Keseimbangan, Lunges, Squat, Pencak Silat 


\title{
LUNGES TRAINING IS BETTER THAN SQUAT TRAINING IN IMPROVES STRENGTH OF LEG MUSCLE AND BALANCE IN MALE ATHLETES OF PENCAK SILAT EXTRACURRICULAR PARTICIPANTS AT DWIJENDRA HIGH SCHOOL DENPASAR
}

\begin{abstract}
The strength of leg muscle and balance are factors that determine of kicks quality in pencak silat, this training methods on leg muscle strength and balance are needed through more effective movements. Lunges and squats are exercises to improve leg muscle strength and balance. The purpose of this study is to prove lunges training better than squats in improving leg muscle strength and balance of male athletes of pencak silat extracurricular participants at Dwijendra high school Denpasar. This type is true experimental research with randomized pre-test and post-test with control groups design. The subjects of this study were 18 male athletes of pencak silat extracurricular participants at Dwijendra high school Denpasar who were divided into two different groups. Group 1 exercise lunges while Group 2 exercises squat, exercises given for 6 weeks with a frequency of 3 times a week. Measurement using leg dynamometer to determine leg muscle strength and standing stork test to determine balance. The mean measurement of leg muscle strength before lunges exercises $177.44 \pm 7.69 \mathrm{~kg}$ while after lunges exercises $205.44 \pm 9.50 \mathrm{~kg}$. The mean measurement of leg muscle strength before squat exercises $172.33 \pm 7.84 \mathrm{~kg}$ while after squat exercises $187.22 \pm 7.32 \mathrm{~kg}$. The mean balance measurement results before lunges exercise 18.11 \pm 1.61 seconds while after lunges training $27.22 \pm 1.98$ seconds. The mean balance measurement results before squat exercises were $18.44 \pm 1.87$ seconds while after squat exercises were $23.11 \pm 1.36$ seconds. The average difference test of leg muscle strength and balance in Group 1 and Group 2 with the independent test on the post test showed the value of $p=0.00(p<0.05)$. Group 1 and Group 2 both gave an increase in leg muscle strength and balance in male athletes of pencak silat extracurricular participants at Dwijendra high school Denpasar, but Group 1 was better than Group 2 in terms of the post test average. Suggestions in this study are expected to the trainers can provide training appropriately and in accordance with the methods and principles in training order to be able to improve athlete's achievement.
\end{abstract}

Keywords: Leg Muscle Strength, Balance, Lunges, Squat, Pencak Silat

\section{PENDAHULUAN}

Untuk dapat melakukan teknik dengan baik sangat diperlukan kemampuan fisik yang optimal. Olahraga pencak silat memerlukan kemampuan fisik seperti reaksi, kecepatan, koordinasi, daya tahan, kelincahan, kekuatan, kelentukan dan ketepatan pada bidang sasaran. Penguasaan teknik bagi atlet pencak silat sangatlah penting untuk menunjang prestasi khususnya pada teknik serangan menggunakan kaki atau tendangan. Serangan yang sah dengan teknik tendangan lebih tinggi pointnya dari pada serangan yang menggunakan teknik pukulan. Teknik tendangan sering digunakan untuk memperoleh point dalam pertandingan pencak silat. ${ }^{1}$
Kualitas tendangan ditentukan oleh faktor kekuatan dan keseimbangan. Saat melakukan tendangan, apabila otot tungkai tidak kuat maka mempengaruhi hasil dari tendangan yang dilakukan. Tendangan yang lemah membuat kaki mudah ditangkap oleh lawan, jika keseimbangan buruk akan mudah dijatuhkan. Sehingga dapat dikatakan, kekuatan otot tungkai dan keseimbangan merupakan komponen yang menentukan untuk mencapai potensi optimal.

Berdasarkan dari pengamatan serta pengalaman di lapangan prestasi atlet pencak silat SMA Dwijendra Denpasar cenderung terjadi penurunan, dibuktikan dalam pertandingan Pekan Olahraga Pelajar Kota Denpasar. Saat memberikan serangan kepada 
lawan, tendangan dari atlet SMA Dwijendra Denpasar yang diarahkan kepada lawan sangat lemah dan kurang optimal, membuat lawan mudah menangkap dan membanting sehingga menyebabkan poin lawan terus bertambah. Peluang besar untuk meraih poin adalah melalui tendangan. Atlet pencak silat SMA Dwijendra Denpasar juga kurang mendapatkan latihan meningkatkan kekuatan otot tungkai, bahkan latihan yang didapat cenderung tidak terprogram.

Latihan yang mampu meningkatkan kekuatan otot tungkai dan keseimbangan salah satunya latihan lunges, yang bertujuan meningkatkan perkembangan dan kekuatan otot bagian bawah tubuh bagian bawah. Latihan lunges melatih otot oblique, quadriceps, gluteus. Pemberian stabilisasi dari gerakan di sekitar sendi pergelangan kaki akan melatih otot tungkai lebih baik. Latihan lunges juga untuk meningkatkan keseimbangan dan koordinasi tubuh. $^{2}$

Latihan lain meningkatkan kekuatan dari otot tungkai dan keseimbangan adalah latihan squat. Gerakan ini termasuk ke dalam gerakan yang cukup sederhana, dari posisi berdiri kemudian badan di jongkokkan lalu kembali ke posisi awal. Dalam melakukan gerakan squat harus mempunyai kekuatan yang baik, bagi orang dengan kekuatan yang buruk di sarankan agar melakukan latihan squat tanpa beban. Gerakan squat adalah gerakan yang termasuk gerakan weight training yang meningkatkan kekuatan dan mengembangkan otot tungkai seperti gluteus maximus, quadriceps dan hamstrings. ${ }^{3}$

\section{METODE PENELITIAN}

Penelitian dilakukan di SMA Dwijendra Denpasar, waktu dan pengambilan data pada bulan Desember 2019 s/d Januari 2020, Latihan selama 6 minggu dengan frekuensi 3 kali latihan dalam seminggu (Senin, Rabu dan Jumat) pukul 16:00 s/d 18:00 WITA. Jenis penelitian true eksperimental dengan rancangan randomized pretest and posttest with control group design.

Penelitian dilakukan untuk mengetahui pelatihan lunges lebih baik daripada pelatihan squat dalam mengikatkan kekuatan otot tungkai dan keseimbangan pada atlet putra peserta ekstrakurikuler pencak silat SMA Dwijendra Denpasar. Pengukuran kekuatan otot tungkai leg dynamometer dan standing stork test digunakan untuk mengukur kekuatan otot tungkai dan keseimbangan.

\section{A. Populasi dan sampel}

Sampel diambil menggunakan random sampling menggunakan rumus Pocock yang berjumlah 18 orang, sampel pada penelitian ini di dibagi ke dalam dua kelompok berdasarkan kriteria eksklusi dan inklusi. Kelompok 1 latihan lunges, Kelompok 2 latihan squat. Pelatihan di lakukan dengan frekuensi 3 kali latihan selama 6 minggu.

\section{B. Pengumpulan Data}

Meminta persetujuan kepada responden (inform consent) lalu diberikan penjelasan secara tertulis dan lisan mengenai tujuan penelitian, hak responden, manfaat penelitian. Selanjutnya dilakukan pretest guna mengetahui kekuatan otot tungkai serta keseimbangan, Kelompok 1 latihan lunges 8 repetisi 5 set selama 6 minggu dan Kelompok 2 latihan squat 8 repetisi dengan 5 set selama 6 minggu. Setelah melakukan pelatihan masing-masing kelompok melakukan post test.

\section{Analisis Data}

\section{Uji Normalitas}

Berdasarkan dari hasil pengujian Normalitas data (Shapiro-walk test) kekuatan otot tungkai serta keseimbangan data sebelum dan sesudah dari pelatihan Kelompok 1 dan Kelompok 2 menunjukkan hasil nilai $\mathrm{p}$ ke dua kelompok di atas 0,05 atau $p$ lebih besar dari $(\mathrm{p}<0,05)$, sehingga data penelitian berdistribusi normal.

\section{Uji Homogenitas}

Berdasarkan dari hasil uji Homogenitas data menggunakan Levenes Test menunjukkan hasil nilai $\mathrm{p}$ ke dua Kelompok di atas 0,05 atau $\mathrm{p}$ lebih besar dari $(p<0,05)$ sehingga data penelitian bersifat homogen.

\section{Uji Hipotesis}

Uji hipotesis 1 dan 2 menggunakan paired $t$ test dalam mengetahui perbedaan dari efek latihan lunges terhadap peningkatan kekuatan otot tungkai dan keseimbangan, untuk menguji 
kemaknaan data sebelum dan sesudah pada Kelompok 1.

Uji Hipotesis 3 dan 4 menggunakan paired $t$ test dalam mengetahui perbedaan dari efek latihan squat terhadap peningkatan kekuatan otot tungkai dan keseimbangan, untuk menguji kemaknaan data sebelum dan sesudah pada Kelompok 2.

Uji hipotesis 5 dan 6 menggunakan independent t test dalam mengetahui perbedaan pelatihan lunges dan squat terhadap peningkatan kekuatan otot tungkai dan keseimbangan, untuk menguji kemaknaan pada ke dua kelompok.

\section{HASIL PENELITIAN}

\section{A. Karakteristik Subjek Penelitian}

Karakter dari subjek penelitian terdiri dari umur, tinggi badan dan berat badan dapat di lihat pada Tabel 1.

\section{Tabel 1.}

Distribusi Data Subjek Berdasarkan Umur, Tinggi Badan, Berat Badan Ke Dua Kelompok

\begin{tabular}{cll}
\hline Karakteristik Subjek & $\begin{array}{l}\text { Kelompok 1 } \\
(\text { Rerata } \pm \text { SB) }\end{array}$ & $\begin{array}{l}\text { Kelompok 2 } \\
(\text { Rerata } \pm \text { SB) }\end{array}$ \\
\hline Umur $($ th) & $16,44 \pm 0,52$ & $16,70 \pm 0,44$ \\
Tinggi Badan $(\mathrm{cm})$ & $170,78 \pm 2,10$ & $169,67 \pm 4,41$ \\
Berat Badan $(\mathrm{kg})$ & $66,24 \pm 7,47$ & $64,20 \pm 8,49$ \\
\hline
\end{tabular}

Berdasarkan Tabel 1. dapat di lihat karakteristik dari ke dua kelompok pelatihan dalam kondisi hampir sama berdasarkan umur, tinggi badan dan berat badan tidak mempengaruhi penelitian ini.

\section{B. Uji Normalitas dan Homogenitas}

Data sebelum dan sesudah pelatihan berdasarkan uji Normalitas dan homogenitas terhadap ke dua kelompok bisa di lihat pada Tabel 2.

Tabel 2

Uji Normalitas dan Homogenitas Kekuatan Otot Tungkai dan Keseimbangan Sebelum dan

Sesudah pada Pelathan Ke dua Kelompok.

\begin{tabular}{cccc}
\hline \multirow{2}{*}{$\begin{array}{c}\text { Pengukuran } \\
\text { Kekuatan Otot } \\
\text { Tungkai }\end{array}$} & \multicolumn{2}{c}{ Uji Normalitas } & Uji \\
\cline { 2 - 4 } & $\begin{array}{c}\text { Kelompok 1 } \\
\text { Nilai p }\end{array}$ & $\begin{array}{c}\text { Kelompok 2 } \\
\text { Nilai p }\end{array}$ & Nilai p \\
\hline Pre test & 0,415 & 0,842 & 0,797 \\
Post test & 0,617 & 0,323 & 0,315 \\
\hline \multirow{2}{*}{ Pengukuran } & \multicolumn{2}{c}{ Uji Normalitas } & Uji \\
\cline { 2 - 4 } Keseimbangan & Kelompok 1 & Kelompok 2 & Nilai p \\
& Nilai p & Nilai p & Hogenitas \\
\hline
\end{tabular}

\begin{tabular}{cccc}
\hline Pre test & 0,481 & 0,288 & 0,560 \\
Post test & 0,299 & 0,494 & 0,481 \\
\hline
\end{tabular}

Berdasarkan uji Normalitas data (Shapirowalk test) ke dua kelompok menunjukkan ( $\mathrm{p}>0,05)$ atau $\mathrm{p}$ value lebih besar dari 0,05. Berdasarkan uji Homogenitas data (Levenes Test) ke dua kelompok menunjukkan ( $\mathrm{p}>0,05)$ atau $\mathrm{p}$ lebih besar dari 0,05

\section{Hasil Uji Beda Kekuatan Otot Tungkai dan Keseimbangan Sebelum dan Sesudah Pelatihan Pada Masing-Masing Kelompok Penelitian}

Uji rerata perbedaan sebelum dan sesudah pelatihan kekuatan otot tungkai dan keseimbangan dapat dilihat pada Tabel 3.

Tabel 3

Uji Rerata Perbedaan Peningkatan Kekuatan Otot Tungkai dan Keseimbangan Sebelum dan Sesudah Pelatihan

\begin{tabular}{ccccc}
\hline $\begin{array}{c}\text { Pengukuran } \\
\text { Kekuatan Otot } \\
\text { Tungkai }\end{array}$ & $\begin{array}{c}\text { Sebelum } \\
(\text { Rerata } \pm \text { SB) }\end{array}$ & $\begin{array}{c}\text { Sesudah } \\
(\text { Rerata } \pm \text { SB })\end{array}$ & t & $\mathrm{p}$ \\
\hline Kelompok 1 & $177,44 \pm 7,69$ & $205,44 \pm 9,50$ & $-8,198$ & 0,000 \\
Kelompok 2 & $172,33 \pm 7,84$ & $187,22 \pm 7,32$ & $-8,826$ & 0,000 \\
\hline $\begin{array}{c}\text { Pengukuran } \\
\text { Keseimbangan }\end{array}$ & $\begin{array}{c}\text { Sebelum } \\
(\text { Rerata } \pm \text { SB) }\end{array}$ & $\begin{array}{c}\text { Sesudah } \\
(\text { Rerata } \pm \text { SB })\end{array}$ & t & $\mathrm{p}$ \\
\hline Kelompok 1 & $18,11 \pm 1,61$ & $27,22 \pm 1,98$ & - & 0,000 \\
Kelompok 2 & $18,44 \pm 1,87$ & $23,11 \pm 1,36$ & $-8,083$ & 0,000 \\
\hline
\end{tabular}

Berdasarkan hasil uji rerata pada tabel di atas menunjukan $(\mathrm{p}>0,05)$ atau $\mathrm{p}$ lebih kecil dari 0,05 yang membuktikan adanya peningkatan bermakna terhadap kekuatan otot tungkai dan keseimbangan ke dua Kelompok.

\section{Uji Beda Kekuatan Otot Tungkai dan Keseimbangan Sesudah Pelatihan Antar Kelompok Penelitian}

Uji beda efek antar kelompok dalam menentukan hasil akhir Kekuatan otot tungkai dan keseimbangan dapat di lihat pada Tabel 4.

\begin{tabular}{ccccc}
\hline $\begin{array}{c}\text { Pengukuran } \\
\text { Kekuatan Otot } \\
\text { Tungkai }\end{array}$ & Kelompok 1 & Kelompok 2 & $\mathrm{t}$ & $\mathrm{p}$ \\
\hline Sebelum & $177,44 \pm 7,69$ & $172,33 \pm 7,84$ & 1,395 & 0,182 \\
Sesudah & $205,44 \pm 9,50$ & $187,22 \pm 7,32$ & 4,556 & 0,000 \\
\hline Pengukuran & Kelompok 1 & Kelompok 2 & $\mathrm{t}$ & $\mathrm{p}$ \\
Keseimbangan & & & & \\
\hline Sebelum & $18,11 \pm 1,61$ & $18,44 \pm 1,87$ & $-0,404$ & 0,692 \\
Sesudah & $27,22 \pm 1,98$ & $23,11 \pm 1,36$ & 5,119 & 0,000 \\
\hline
\end{tabular}

Tabel 4 
Uji Perbedaan Efek Antar Kelompok Dalam

Menentukan Hasil Akhir Kekuatan Otot

Tungkai dan Keseimbangan

Berdasarkan uji beda rerata hasil pengukuran sebelum pelatihan pada kelompok 1 dan kelompok 2, nilai $(\mathrm{p}<0,05)$ atau $\mathrm{p}$ lebih besar dari 0,05 menunjukkan tidak ada perbedaan yang bermakna sebelum pelatihan.

Berdasarkan uji beda rerata hasil pengukuran sesudah dari pelatihan pada Kelompok 1 dan Kelompok 2 dengan ( $>0,05)$ sehingga menunjukkan adanya perbedaan yang bermakna sesudah pelatihan.

\section{PEMBAHASAN}

\section{Peningkatan Kekuatan Otot Tungkai Setelah Latihan Lunges}

Latihan lunges termasuk dalam latihan untuk otot tungkai, melalui teknik berdiri dengan satu kaki dan juga jongkok serta keadaan kaki di jaga agar membentuk sudut $90^{\circ}$ kemudian kaki bagian belakang ditekuk sampai sudut $45^{0}$, yaitu lurus sejajar dengan tubuh, beban yang digunakan dalam latihan ini menggunakan berat badan sendiri. Lunges membangun kekuatan otot tungkai, stabilitas bagian tengah tubuh meningkat, dan dapat mengencangkan bagian otot sehingga dapat menyeimbangkan pertumbuhan otot dan menyeimbangkan kekutan. ${ }^{4}$

Latihan lunges merupakan latihan untuk meningkatkan otot bagian bawah, otot yang dilatih adalah otot quadriceps, hamstrings, gluteus, oblique, dan otot betis. Dengan stabilisasi gerakan dari sekitar sendi bagian pergelangan kaki, latihan lunges juga sebagai suatu latihan dalam meningkatkan koordinasi tubuh dan keseimbangan. ${ }^{2}$ Beban merupakan cara agar mampu menerapkan suatu prosedur pada bagian otot tubuh. Kondisi ini sangat efektif untuk meningkatkan kekuatan dari otot, ketahanan otot dapat menggunakan bantuan alat (dumbbell dan barbel) atau menggunakan berat dari tubuh sendiri. ${ }^{5}$

\section{Peningkatan Kekuatan Otot Tungkai Setelah Pelatihan Squat}

Gerakan latihan squat menggunakan beban dari tubuh sendiri atau dengan suatu dumbbell dan barbel, melalui frekuensi, set, lama latihan dan intensitas sehingga menimbulkan peningkatan kekuatan, daya tahan dan daya ledak. Kemampuan fisik yang meningkat maka bertambah pula kemampuannya tersebut secara umum. $^{6}$ pelatihan squat melibatkan komponen otot besar seperti otot quadriceps, hamstrings dan gluteus maximus. Pelatihan beban yang melibatkan bagian besar otot lebih efektif untuk meningkatkan kekuatan yang akan berimbas pada peningkatan keterampilan dalam olahraga. $^{7}$

Latihan squat merupakan latihan beban yang penting dalam meningkatkan otot tungkai, pelatihan ini ada 2 jenis yaitu menggunakan alat dan menggunakan berat badan sendiri. Ketika melakukan gerakan tersebut diharapkan mempunyai kekuatan dasar yang baik, untuk seseorang yang memiliki kelentukan dan kekuatan dasar yang buruk makan disarankan agar tidak menggunakan beban terlebih dahulu saat melakukan gerakan squat. ${ }^{3}$

\section{Pelatihan Lunges Lebih Baik Daripada Pelatihan Squat dalam Meningkatkan Kekuatan Otot Tungkai}

Hasil peningkatan rerata kekuatan otot tungkai ke dua kelompok mempunyai hasil yang bermakna merupakan dampak dari latihan yang diberikan. Atlet yang diberikan pelatihan 4 s/d 8 minggu dengan frekuensi 3 s/d 4 kali seminggu membuat tubuh beradaptasi dengan latihan yang diberikan dan terjadi peningkatan yang bermakna. ${ }^{8}$

Jika otot terus dilatih maka otot akan terus bertambah kuat dan memiliki ketahanan yang meningkat, pelatihan beban minimal 3 kali seminggu dapat menambah kekuatan dan ketahanan otot sekitar 25-100\%. ${ }^{9}$ Adaptasi yang terjadi dari pelatihan beban adalah bertambahnya masa otot yang merupakan jumlah miosin dan filamin aktin dalam miofibril yang menyebabkan membesarnya diameter serabut otot. ${ }^{10}$ Pada pelatihan ini, lunges dan squat meningkatkan jumlah sarkoplasma, filamen aktin, miofibril, miosin, enzim mitokondria, metabolisme fosfagen, termasuk ATP fosfokreatin, cadangan glikogen dan trigliserida. $^{11}$

Latihan lunges memiliki progresivitas yang lebih baik karena gerakan pelatihan lunges menggunakan satu kaki tumpu untuk berdiri pada saat pelatihan dan posisi badan yang 
condong ke depan memberikan efek beban yang lebih besar, sehingga membuat kekuatan otot tungkai menjadi lebih optimal. Sedangkan pelatihan squat menggunakan dua kaki tumpu secara bersamaan pada saat melakukan gerakan, ini membuat beban pelatihan dibagi menjadi dua karena menggunakan dua kaki tumpu secara bersamaan pada saat pelatihan.

\section{Peningkatan Keseimbangan Setelah Pelatihan Lunges}

Latihan lunges dilakukan menggunakan beban diri sendiri, hal ini terbilang sulit ketika melakukan pelatihan ini dikarenakan selain melatih keseimbangan namun juga melatih kekuatan lunges karena bentuk pelatihan nya yang menggunakan satu kaki tumpu. ${ }^{12}$ Latihan keseimbangan berdiri dengan satu kaki dapat memberikan perubahan secara fisiologis terhadap tubuh manusia yang akan meningkatkan keseimbangnnya. ${ }^{13}$

Kekuatan otot tungkai memiliki hubungan erat dengan keseimbangan tubuh, peran dari kekuatan otot tungkai adalah suatu penggerak dari setiap aktifitas fisik, kekuatan dari otot pinggul, lutut serta kaki yang dituntut kuat agar mampu menyeimbangkan tubuh ketika terjadi suatu gaya dari luar. Hubungan kemampuan otot dengan kekuatan otot memiliki hubungan dalam melawan beban eksternal dan gaya gravitasi secara menerus sehingga mempengaruhi posisi dari tubuh. Semakin baik kekuatan otot tersebut maka semakin baik juga keseimbangan tubuh. ${ }^{14}$

\section{Peningkatan Keseimbangan Setelah Pelatihan Squat}

Pelatihan squat merupakan suatu jenis pelatihan beban dalam meningkatkan atau mengembangkan kekuatan otot tungkai dan sebagai beban dasar pelatihan. Pelatihan squat menggunakan beban dari diri sendiri atau dengan barbel. Set, frekuensi, lama latihan, intensitas dapat menimbulkan efek pelatihan yang menyebabkan meningkatnya kekuatan. ${ }^{15}$

Faktor yang paling berpengaruh dalam keseimbangan adalah kekuatan otot ekstensor tungkai, sesuai dengan pernyataan di atas, bahwa pelatihan yang mampu meningkatkan kekuatan otot tungkai akan meningkatkan keseimbangan. ${ }^{16}$ hal inilah yang di dukung oleh hasil penelitian yang menyatakan pelatihan penguatan otot memberikan efek yang signifikan terhadap keseimbangan. ${ }^{17}$

\section{Pelatihan Lunges Lebih Baik Daripada Pelatihan Squat Dalam Meningkatkan Keseimbangan}

Latihan

lunges meningkatkan

keseimbangan dari pada pelatihan squat, seiring gerakan lunges yang memerlukan koordinasi dan keseimbangan tubuh, hampir semua otot dalam tubuh akan bekerja menyesuaikan diri dengan pelatihan tersebut. Latihan lunges meningkatkan kekuatan otot bagian bawah tubuh seperti otot quadriceps, gluteus, oblique. Latihan lunges juga sebagai latihan meningkatkan koordinasi dan keseimbangan tubuh, sehingga sangat baik digunakan dalam meningkatkan keseimbangan. Otot yang berperan dalam menjaga keseimbangan akan melakukan kontraksi untuk menjaga bagian atas tubuh dan bawah tubuh agar tetap terkoordinasi dengan cukup baik. Ketika latihan lunges maka tubuh harus mampu menjaga kesamaan antara sendi pada pergelangan kaki, lutut, dan pinggul dalam menjaga keseimbangan. Posisi dan gerakan latihan lunges memberikan perlawanan gaya gravitasi dan beban eksternal yang lebih besar dibandingkan posisi dan gerakan pelatihan squat. $^{2}$

Pusat gravitasi adalah suatu hal utama dari bagian tubuh yang mendistribusikan massa tubuh dengan merata. Jika tubuh berdiri pada kondisi ini maka keadaan menjadi seimbang. ${ }^{3}$ Kerusakan kontrol postural merupakan kombinasi dari kerusakan proprioseptif dan kontrol neuromuscular. Saat berdiri dengan satu kaki, kaki akan berpronasi dan bersupinasi untuk mempertahankan centre of gravity. ${ }^{18}$

Kemampuan tubuh untuk menjaga keseimbangan dari aktivitas motorik tidak mampu dijauhkan dari faktor-faktor lain seperti sistem regulasi dan faktor lingkungan yang memiliki peran khusus untuk proses keseimbangan. Beberapa komponen secara fisiologi, manusia memungkinkan melakukan reaksi keseimbangan, reseptor sensorik dari seluruh otot, kulit, ligamen dan sendi mampu memberikan perubahan lingkungan secara eksternal dan internal yang mampu meningkatkan keseimbangan. Proprioseptif bertugas dalam hal mempertahankan gerakan keseimbangan, yang dihasilkan melalui sistem 
visual yang direspon secara simultan. Sensorik otot dan sistem vastibular berperan penting menjaga stabilitas postural, yang berguna untuk keseimbangan tubuh akan diproses oleh reseptor proprioseptif dan visual. ${ }^{19}$

Keseimbangan terjadi ketika integritas antara vestibular, proprioseptif, visual, sistem saraf pusat dan neuromusculoskeletal sebagai faktor respon motorik dalam merespon perubahan gravitasi. Sistem proprioseptif mempunyai peranan untuk mempertahankan keseimbangan yang memiliki hubungan dengan traktus spinocerebellar anterior dan posterior. Sinyal inilah yang menghubungkan traktus spinocerebellar posterior yang berasal dari reseptor seluruh tubuh, reseptor taktil yang berada pada kulit, organ tendon golgi, reseptor sendi. Semuanya hal ini menginformasikan kepada cerebellum mengenai keadaan dari tubuh. ${ }^{20}$

Sistem proprioseptif sensitif pada perubahan cepat pada posisi tubuh, sistem visual lebih sensitif pada kondisi tubuh yang mengalami perubahan secara lambat. Jika seseorang berada pada posisi berdiri diatas permukaan miring, kemudian bergerak atau berdiri dengan satu kaki, otot tubuh akan berkontraksi cepat untuk mengembalikan posisi tubuh dalam keadaan yang seimbang. ${ }^{21}$

Sejumlah komponen otot yang baik pada ekstremitas bawah atau atas dapat berfungsi menjaga postur dari seseorang ketika berdiri tegak dalam mengatur tubuh agar tetap seimbang dalam berbagai posisi. Keseimbangan memungkinkan otot postural bekerja sinergi untuk reaksi akibat perubahan tubuh dari gaya gravitasi dan titik tumpu. Kekuatan otot yang umumnya mempengaruhi komponen keseimbangan dalam melakukan aktivitas tertentu. Gerakan yang dihasilkan merupakan hasil dari peningkatan tegangan otot sebagai respon motorik. Penggambaran dari kekuatan otot yang menahan beban eksternal dan internal harus kuat dalam menjaga keseimbangan saat terjadinya gaya dari luar ${ }^{22}$.

Dalam penelitian ini, pelatihan lunges dan squat dengan latihan selama 6 minggu dengan frekuensi 3 kali latihan dapat mengubah keseimbangan. Dilihat dari metode pelatihan lunges yang menggunakan satu kaki tumpu pada saat pelatihan sedangkan pelatihan squat menggunakan dua kaki tumpu pada saat pelatihan. Perbedaan pelatihan ini membuat pelatihan lunges memiliki intensitas yang lebih besar untuk melatih keseimbangan dari pelatihan squat.

\section{SIMPULAN}

1. Pelatihan lunges meningkatkan kekuatan otot tungkai atlet putra peserta ekstrakurikuler pencak silat SMA Dwijendra Denpasar.

2. Pelatihan lunges meningkatkan keseimbangan atlet putra peserta ekstrakurikuler pencak silat SMA Dwijendra Denpasar.

3. Pelatihan squat meningkatkan kekuatan otot tungkai atlet putra peserta ekstrakurikuler pencak silat SMA Dwijendra Denpasar.

4. Pelatihan squat meningkatkan keseimbangan atlet putra peserta ekstrakurikuler pencak silat SMA Dwijendra Denpasar.

5. Pelatihan lunges lebih baik daripada pelatihan squat dalam meningkatkan kekuatan otot tungkai atlet putra peserta ekstrakurikuler pencak silat SMA Dwijendra Denpasar

6. Pelatihan lunges lebih baik daripada pelatihan squat dalam meningkatkan keseimbangan atlet putra peserta ekstrakurikuler pencak silat SMA Dwijendra Denpasar.

\section{SARAN}

1. Kepada para pelatih dan atlet khususnya pada cabang olahraga pencak silat bahwasanya pelatihan lunges lebih efektif dalam meningkatkan kekuatan otot tungkai dan keseimbangan.

2. Hasil dari penelitian ini agar dijadikan evaluasi serta acuan untuk atlet dan pelatih dalam mengevaluasi hasil latihan dan penyusunan program latihan berikutnya untuk meningkatkan prestasi optimal dalam pencak silat.

3. Kepada peneliti berikutnya agar menjadikan penelitian ini sebagai bahan referensi dan perbandingan jika memilih masalah yang sama dalam penelitiannya. 


\section{DAFTAR PUSTAKA}

1. Agung, A.M. 2004. Diktat Pencak Silat.

2. Yogyakarta: PPM FIK-UNY.

3. Kamayoga, D.G.A., Adiputra, N., Lesmana, S.I, 2017. Intervensi Dumbbell Lunges dan Core Stability Exercise Lebih Baik Daripada Intervensi Elastic Band dan Core Stability Exercise Terhadap Peningkatan Keseimbangan Dinamis Pada Pemain Skateboard Dengan Kondisi Chronic Ankle Instability. Sport and Fitness Journal. 5(3): 85-92.

4. Sandler, D. 2010. Fudamental weight training. Canada: Human Kinetics.

5. Khairudin, Afri. 2019. Pengaruh Latihan Single Leg Squat dan Lunges Terhadap Power Otot Tungkai Pemain SSB Baturetno $\mathrm{Ku}$ 14-15 Tahun. E-Journal Kepelatihan Olahraga. 8(6): 1-11.

6. Maulana, S.L., Hadi, S.S. 2015. Latihan Beban Lunges dan Squatter Squat Untuk Meningkatkan Kecepatan Renang Gaya Dada. Journal of Sport Sciences and Fitness. 4(3): 27-31.

7. Rachman, Aryadi. 2014. Pengaruh Latihan Squat dan Leg Press Terhadap Strength dan Hypertrophy Otot Tungkai. Jurnal Multilateral. 13(2): 88-102.

8. Mansur, L.K., Irianto, J.K., Mansur. 2018. Pengaruh Latihan Squat Menggunakan Free Weight dan Gym Machine Terhadap Kekuatan, Power, dan Hypertrophy Otot. Jurnal Keolahragaan. 6(2): 150-161.

9. Nala, I Gusti Ngurah. 2015. Prinsip Pelatihan Fisik Olahraga. Denpasar: Udayana University Press.

10. Plowman, S.A., Smith, D.L. 2011. Exercise Physiology for Health, Fitness, and Performance. Philadelphia: Wolters Kluwer Health.

11. Guyton, Hall. 2011. Textbook of Medical Physiology, 12th edition, Saunder: Elsevier.

12. Sudarsono, Slamet. 2011. Penyusunan Program Pelatihan Berbeban Untuk Meningkatkan Kekuatan. Jurnal Ilmiah Spirit. 11(3): 31-43.

13. Baechle, R Thomas. 2000. Latihan Beban. Jakarta: PT Rajagrafindo Persada.

14. Kaesler, 2007, A Novel Balance Exercise Program for Postural Stability in Older
Adults: A pilot study. Journal of Bodywork and Movement Therapies, 49(11): 37-43.

15. Budiwibowo, F., Anies, S. 2015. Unsur Indeks Massa Tubuh dan Kekuatan Otot Tungkai Dalam Keseimbangan. Journal Of Sport Sciences And Fitness. 4(2): 31-36.

16. Sulisty, Wahyu. 2010. Pengaruh Latihan Half Squat dan Latihan Quarter Squat pada Kecepatan Tendangan dan Daya Ledak Otot Tungkai. Jurnal FKIP UNS. 3(1): 337-448.

17. Suhartono. 2005. Pengaruh Kelelahan Otot Anggota Gerak Bawah Terhadap Keseimbangan Postural Pada Subyek Sehat [tesis]. Semarang: Universitas Diponegoro Semarang.

18. Meyta Tatarina. 2012. Pengaruh Latihan Penguatan Otot Tungkai Bawah Dengan Metode One Repetition Maximum (1RM) Terhadap Tingkat Keseimbangan Lanjut Usia [skripsi]. Surakarta: Universitas Muhammadiyah Surakarta.

19. Hertel, J. 2002. Functional Anatomy, Pathomechanics, and Pathophysiology of Lateral Ankle Instability. Journal of Athletic Training. 37(4): 364-375.

20. Brown, S.P., Miller, W.C., \& Eason, J.M, 2006. Neuroanatomy And Neuromuscular Control Of Movement.Exercise Physiology: Basis Of Human Movement In Health And Disease. Philadephia: Lippincott Williams \& Wilkins. 217-246.

21. Pramadita , Arrilia Putri., Arinta Puspita Wati., Hexanto Muhartomo. 2019. Hubungan Fungsi Kognitif Dengan Gangguan Keseimbangan Postural Pada Lansia. Jurnal Kedokteran Diponegoro. 8,(2): 626-641.

22. Yuliana, S., Adiatmika, I.P.G., Irfan, M. 2014. Pelatihan Kombinasi Core Stability Exercise dan Ankle Strategy Exercise Tidak Lebih Meningkatkan Dari Core Stability Exercise Untuk Keseimbangan Statis pada Mahasiswa S1 Fisioterapi Stikes Aisyiyah Yogyakarta. Sport and Fitness Journal, 2(2): 63-73.

23. Nugroho S. 2011. Materi Kinesiology. Universitas Negeri Yogyakarta. 